\title{
Effectiveness of Mindfulness Meditation Programs in the Promotion of Quality of Life in Patients with Heart Failure: A Systematic Review
}

\author{
Vaisnava Nogueira Cavalcante, ${ }^{\circledR}$ Ana Carla Dantas Cavalcanti, ${ }^{\circledR}$ Juliana de Melo Vellozo Pereira Tinoco, ${ }^{\circledR}$ Lyvia \\ da Silva Figueiredo, ${ }^{(\mathbb{0}}$ Evandro Tinoco Mesquita ${ }^{(-)}$ \\ Universidade Federal Fluminense, Niterói, RJ - Brazil
}

\section{Abstract}

Background: Despite optimal medical treatment, many heart failure (HF) patients continue to show a high prevalence of symptoms, which contributes to a high morbidity and poor health-related quality of life (HRQL). Mindfulness meditation may be effective in improving the quality of life in these patients.

Objective: A systematic review was conducted to evaluate if mindfulness meditation programs are effective in promoting and improving the quality of life in patients with heart failure.

Methods: The PubMed (MEDLINE), Cumulative Index of Nursing and Allied Health (CINAHL), LILACS, Cochrane Library, and Scopus databases were searched between October and November of 2019. Articles were selected if they evaluated mindfulness intervention, with an experimental or quasi-experimental design, in adults with heart failure and measured health-related quality of life.

Results: This systematic review identified 108 studies through database searches. After applying the inclusion and exclusion criteria, a total of three studies were considered qualified. These studies took place in the Netherlands, the USA, and Brazil, and occurred between 2005 and 2015. Sample sizes varied from 19 to 215, and the average range of participants within each study varied from 43.2 to 75.4 years. Compared to control programs, mindfulness-based meditation programs improved the quality of life in two studies $(p=0.041$ and $p=0.03)$.

Conclusion: Mindfulness-based meditation programs improved the quality of life in patients with HF. Therefore, there is limited data to strengthen this recommendation to this population, and future research is warranted in order to present consistency in the intervention protocols.

Keywords: Heart Failure Awarence; Mindfulness; Knowledge; Meditation; Quality of Life.

\section{Introduction}

Heart failure (HF) is a disabling illness with significant morbidity and mortality, affecting at least 26 million people worldwide, and is increasing in prevalence. ${ }^{1}$

In spite of optimal medical treatment, many patients continue to show a high prevalence of symptoms, ${ }^{2-6}$ including dyspnea, fatigue, edema, ${ }^{7}$ as well as psychosocial distress..$^{8-11}$ This burden of symptoms contributes to a high morbidity and poor health-related quality of life HRQoL. ${ }^{7,12,13}$ The HF patient's quality of life itself is associated with prognosis, hospitalizations, and mortality. ${ }^{14,15}$
Mindfulness is described as the ability to pay attention in a particular way: on purpose, at the present moment, and non-judgmentally. ${ }^{16}$ Mindfulness-based intervention (MBI) includes meditative exercises, using focused breathing as a tool, and has been effective in reducing stress, anxiety, and depressive symptoms, ${ }^{17,18}$ as well as in improving physical functioning ${ }^{17,19,20}$ and decreasing cardiovascular sympathetic activity in randomized controlled trials- RCTs. ${ }^{19,} 20$

Over the past decade, many RCT's have presented evidence on the effectiveness of MBI in several chronic conditions, such as cancer, depression, chronic pain, 
and eating disorders. ${ }^{21-24}$ However, few studies have specifically explored this kind of intervention in HF patients.

Therefore, the aim of this article is to provide information regarding an additional treatment option for patients with heart failure - mindfulness meditation programs - and to evaluate their effectiveness. A systematic review was conducted to answer the $\mathrm{PICO}^{25}$ (Problem/Population, Intervention, Comparison, and Outcome) question: "How are mindfulness meditation programs effective in promoting and improving the quality of life in patients with heart failure?"

\section{Methods}

\section{Search strategy and selected studies}

The PubMed (MEDLINE), Cumulative Index of Nursing and Allied Health (CINAHL), LILACS, Cochrane Library, and Scopus databases were searched between October and November of 2019, using the Descriptors in Health Sciences (DeCS) and MeSH (Medical Subject Headings) terms.

The following controlled descriptors cited below were used for all databases equally, using the boolean "and" operators for search: heart failure, mindfulness, meditation, and quality of life. Due to the specific characteristics of each database, search strategies were adapted according to the purpose and inclusion criteria of this study.

This study's population included adults over 18 years of age, with heart failure, whether hospitalized or in outpatient follow-up, who evaluated mindfulness meditation programs that have been effective in patients' quality of life.

\section{Study quality evaluation}

Due to the need to evaluate only the interventions with better methodological rigor and effective results in the presented outcomes, this systematic review performed only quantitative content analysis of the following studies: those with an experimental or quasi-experimental design, such as studies without randomization with a single pre- and post-test; time series or control case; indexed in databases published in English, Spanish, or Portuguese, with a temporal cut between 2004 and 2019. The exclusion criteria were studies with no clear determination of methodology, theses and dissertations, and online publications that were impossible to access or print.

In order to reduce the risk of publication bias, full articles were made available for two evaluators to carry out an independent analysis. For this assessment, the Joana Briggs Institute Checklists ${ }^{26,27}$ were used and those articles with a maximum of 3 negative items were deemed eligible.

Of three selected articles, two studies completed 11 items out of the 13 approved in the Randomized Controlled Trials (RCT) Checklist ${ }^{26}$ and 1 article completed 8 items out of the 11 approved in the Cohort Study Checklist. ${ }^{27}$

\section{Data extraction and Analysis}

The titles and abstracts were evaluated separately by two independent evaluators. A database was constructed with the following information of each article found: year, journal / author, objectives, methods, interventions performed, sample size, evaluated outcomes, results, and conclusion, as well as the final evaluation of the inclusion or exclusion of justified studies, according to the criteria described above.

A descriptive analysis of the results found in the selected articles was performed, including study objectives, type of intervention, scenarios, sample characteristics, follow-up time, and outcomes.

\section{Registration}

This systematic review was registered on PROSPERO (International Prospective Register of Systematic Reviews) platform under the number CRD42020153597.

\section{Results}

\section{Search results}

This systematic review identified 108 studies through database searches. After applying the inclusion and exclusion criteria, a total of 3 studies were qualified for this review, ${ }^{20,28,29}$ revealing a limited number of studies addressing QoL as an outcome in patients undergoing a mindfulnessbased intervention. The higher scores meant a better methodological quality and are represented in Table 1. 
Table 1 - Summary of studies reviewed and Quality scores of reviewed studies. Potential range 0-13 for randomized controlled trials and 0-11 for cohort study

\begin{tabular}{|c|c|c|c|c|c|c|c|}
\hline $\begin{array}{l}\text { Author/ } \\
\text { Year }\end{array}$ & Sample & $\mathbf{N}$ & Intervention & Dose & QoL Measures & Effect & $\begin{array}{c}\text { Quality } \\
\text { Score }\end{array}$ \\
\hline $\begin{array}{l}\text { Curiati }^{28} \\
2005\end{array}$ & $\begin{array}{l}\text { Elderly } \\
\text { with HF } \\
\text { classes } \\
\text { I-II }\end{array}$ & $\begin{array}{c}19 \\
\text { Intervention } \\
\quad=10\end{array}$ & $\begin{array}{l}\text { Group meditation, } \\
\text { including } \\
\text { mindfulness } \\
\text { techniques }\end{array}$ & $\begin{array}{c}2 \text { hours of learning } \\
\text { technique class, plus } \\
\text { daily audio guided } \\
\text { meditation for } 30 \\
\text { minutes twice per day } \\
\text { for } 12 \text { weeks }\end{array}$ & $\begin{array}{c}\text { Minnesota } \\
\text { Living with } \\
\text { Heart Failure } \\
\text { Questionnaire }\end{array}$ & $\begin{array}{l}\text { Significant } \\
\text { improvement in } \\
\text { the meditation } \\
\text { group } \\
(\mathrm{p}=0.047)\end{array}$ & $11(13)$ \\
\hline $\begin{array}{l}\text { Sullivan }^{29} \\
2009\end{array}$ & $\begin{array}{l}\text { Adults } \\
\text { with HF } \\
\text { classes } \\
\text { I-IV, FE } \\
\leq 40 \%\end{array}$ & $\begin{array}{c}208 \\
\text { Intervention } \\
=108\end{array}$ & $\begin{array}{l}\text { Mindfulness- } \\
\text { based } \\
\text { psychoeducational } \\
\text { support group }\end{array}$ & $\begin{array}{l}\text { 2.25-hour group } \\
\text { session, weekly } \\
\text { for } 8 \text { weeks, plus } \\
\text { daily audio guided } \\
\text { meditation for } 30 \\
\text { minutes }\end{array}$ & $\begin{array}{c}\text { Kansas City } \\
\text { Cardiomyopathy } \\
\text { Questionnaire } \\
\text { (KCCQ) }\end{array}$ & $\begin{array}{c}\text { Significant } \\
\text { difference over } \\
\text { time in favor of } \\
\text { the treatment } \\
(\mathrm{p}<0.033)\end{array}$ & $8(11)$ \\
\hline $\begin{array}{l}\text { Younge }^{20} \\
2015\end{array}$ & $\begin{array}{c}\text { Adults } \\
\text { with } \\
\text { Heart } \\
\text { Disease, } \\
\text { including } \\
\text { HF }\end{array}$ & $\begin{array}{c}324 \\
\text { Intervention } \\
=215\end{array}$ & $\begin{array}{l}\text { Structured } \\
\text { standardized } \\
\text { online } \\
\text { mindfulness } \\
\text { program }\end{array}$ & $\begin{array}{c}\text { 12-week structured } \\
\text { standardized online } \\
\text { program for self- } \\
\text { directed training, } \\
\text { practical assignments, } \\
\text { and daily meditations }\end{array}$ & $\begin{array}{l}\text { Visual Analogue } \\
\text { Scale }(0-100)\end{array}$ & $\begin{array}{l}\text { No significant } \\
\text { effect on Quality } \\
\text { of Life }\end{array}$ & $11(13)$ \\
\hline
\end{tabular}

A Preferred Reporting Items for Systematic review and Meta-Analysis (P.R.I.S.M.A.) flow diagram outlining the research results is presented in Figure 1.

\section{Study design and samples}

All three of the analyzed studies used controlled groups. Two were randomized controlled trials and one was a cohort study, using a geographic control group ( $>90$ miles from the treatment center). ${ }^{29}$ The studies took place in the Netherlands, the USA, and Brazil, between 2005 and 2015. Sample sizes varied from 19 to 215, and the average range of participants within each study varied from 43.2 to 75.4 years. In two studies, the subjects were exclusively heart failure patients, most of whom were of the NYHA class I and II. In the third study, the patients presented heart failure and other kinds of cardiomyopathy, including ischemic, valvular, and congenital. ${ }^{20}$

\section{Quality of Life measures}

The QoL was measured with different instruments, including the Minnesota Living with Heart Failure Questionnaire (MLHFQ), the Kansas City
Cardiomyopathy Questionnaire (KCCQ), and the Visual Analogue Scale (VAS), which assessed the subjective, self-reported QoL, in which the patients described themselves in terms of overall "quality of life", ranging from 0 to 100, as represented in Table 1.

\section{Intervention}

The study intervention varied. Curiati et al used a meditation program including mindfulness exercises, such as conscious breathing, body scan, and simple self-compassion meditation, and included a relaxation-response technique. ${ }^{28}$ Sullivan et al., developed a mindfulness psychoeducational support group,${ }^{29}$ while Younge et al., worked with a web-based mindfulness intervention. including meditations, self-reflection, and yoga. ${ }^{20}$ Patients had to complete practical questions and assignments in order to be monitored in terms of adherence.

Two studies provided face-to-face meditation sessions ranging from 2 to 2.5 hours plus at least 30 minutes of audio for guided meditation during 8 to 12 weeks. One was an online program of 12 weeks designed to be self-directed. ${ }^{20}$ 

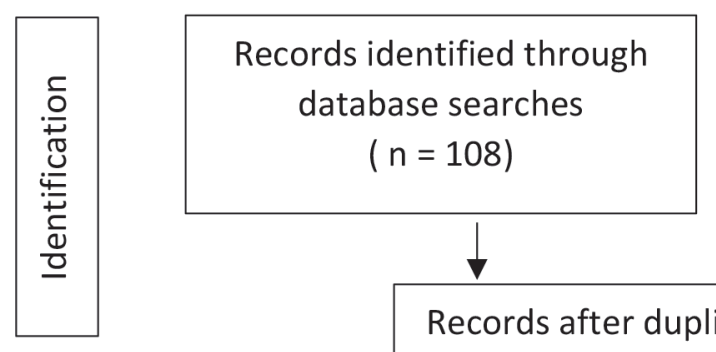

Additional records identified through other sources

$$
(n=0)
$$
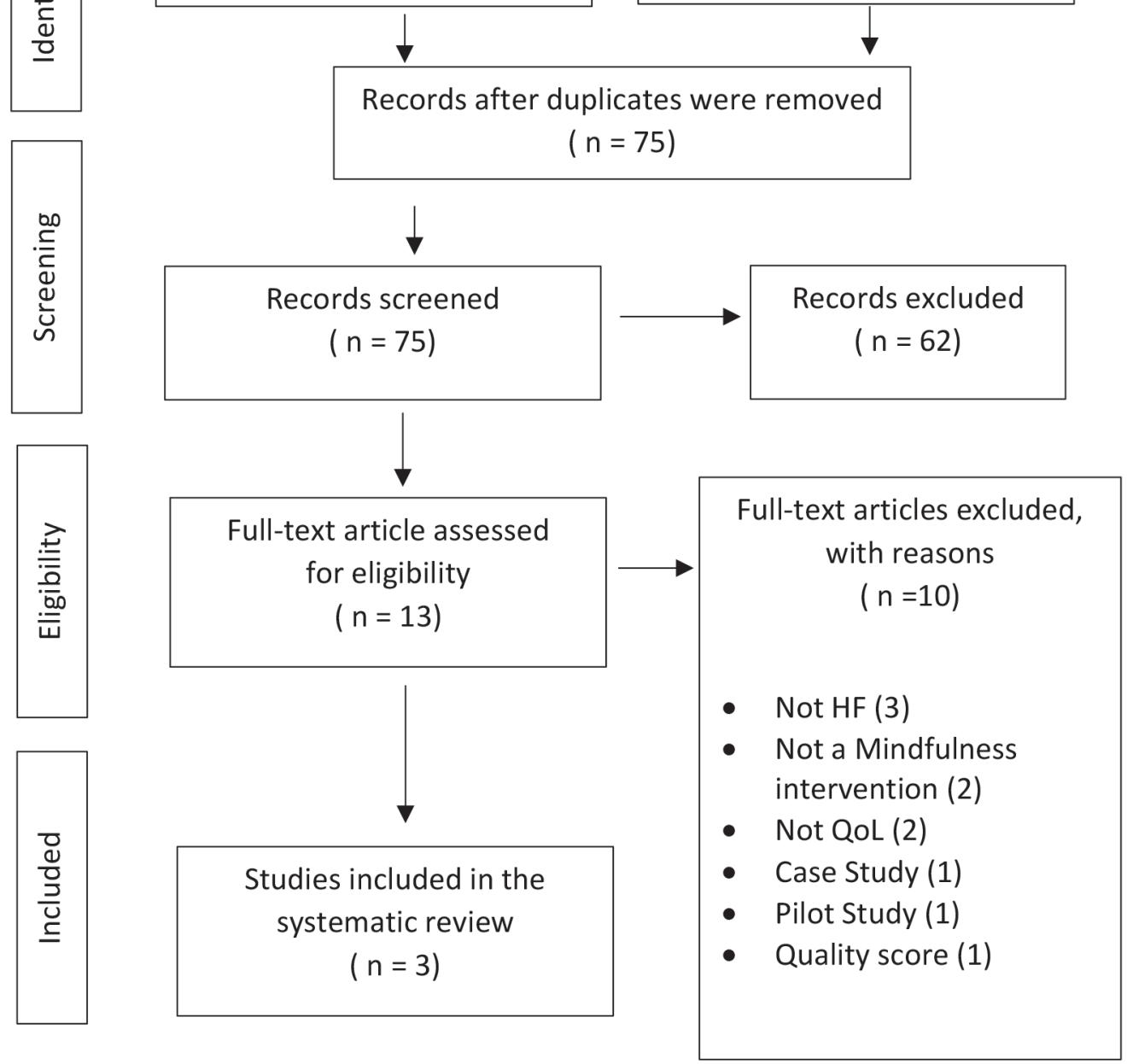

Figure 1 - Preferred Reporting Items for Systematic Review and Meta-Analysis flow diagram. HF indicates heart failure, QoL indicates Quality of life.

\section{Treatment effects}

The two face-to-face studies ${ }^{28,29}$ showed significant improvement in QoL ( $p=0.047$ and $p=0.033)$, while the web-based study did not. ${ }^{20}$ In addition to QoL, a wide range of outcomes were found, including exercise capacity, biomarkers, psychosocial, death and hospitalizations. This fact limited the comparison between studies.

\section{Discussion}

This systematic review evaluated three studies assessing the impact of mindfulness-based meditation programs on the QoL of patients with HF. Besides the relevant fact that quality of life is associated with prognosis, hospitalization, and mortality in HF patients, ${ }^{14}$ previous studies have shown that these subjects prefer quality of life over longevity..$^{30}$

Out of the three evaluated studies, only two showed a significant impact on QoL. The web-based mindfulness program ${ }^{20}$ showed no improvement in QoL or in the other psychological outcomes, although it has presented small positive changes in physiological parameters (functional capacity and heart rate).

Previous studies using web-based mindfulness training was modestly effective in subjective outcomes. ${ }^{31-33}$ The 
authors consider that the impact of the online training could be lower than that of personal in-group training. Nevertheless, online training has the potential to provide easy access and can reach a larger number of people.

The in-person interventions, on the other hand, presented positive trends towards HF patients' QoL, after the mindfulness-based intervention program $(\mathrm{p}=$ 0.047 and $\mathrm{p}=0.033$ )

In the Brazilian study, the total score of QoL improvement was even similar to those obtained with enalapril, suggesting that nonpharmacologic interventions may be as effective as medical treatment. ${ }^{34}$

The American study also showed a significant reduction in anxiety and depression, which may well have contributed to improvement in QoL. ${ }^{29}$ Luskin et al., demonstrated that a psychosocial treatment applying stress management improved this population's quality of life. ${ }^{35}$ In chronic HF, psychosocial copings are strong predictors of quality of life and symptoms regardless of the patient's physiological state. ${ }^{36,37}$

A recent study conducted by Rechenberg et al., showed that total mindfulness (measured by the Five Facets of Mindfulness Questionnaire) was significantly associated with lower anxiety $(\beta=-0.491, P<.01)$, which was in turn associated with greater total QoL $(\beta=0.488$, $\mathrm{P}<.01)$. The author concluded that Mindfulness might be a way of improving this population's QoL. ${ }^{38}$

\section{Limitations}

The small number of studies evaluating the impact of mindfulness-based programs in the QoL of HF patients was a limitation in this systematic review.

The sample size of the studies also limited the recommendation of mindfulness-based intervention to improve the QoL in HF patients. The variation in the intervention protocols, including different techniques,

\section{References}

1. Savarese G, Lund LH. Global Public Health Burden of Heart Failure. Card Fail Rev. 2017; 3(1): 7-11.

2. Barnes S, Gott M, Payne S, Parker C, Seamark D, Gariballa S, Gariballa S,et al. Prevalence of symptoms in a community-based sample of heart failure patients. J Pain Symptom Manag. 2006; 32(3): 208-16.

3. Falk K, Swedberg K, Gaston-Johansson F, Ekman I. Fatigue is a prevalent and severe symptom associated with uncertainty and sense of coherence in patients with chronic heart failure. Eur J Cardiovasc Nurs. 2007; 6(2): 99-104.

4. Falk K, Grange B,, Swedberg K, Ekman I, Breaking the vicious circle of fatigue in patients with chronic heart failure. Qual Health Res. 2007; 17(8):1020-7. length of the programs, daily dose of meditation, and type of interaction (in person or online) also limited the generalization of such interventions in this population.

\section{Conclusion}

According to the reviewed studies, mindfulness-based meditation programs can be useful to improve the QoL of patients with HF.

Coats suggested that this kind of intervention can play an important role in HF treatment programs, ${ }^{39}$ Therefore, future studies are warranted so as to present consistency in the intervention's methodology in order to generalize the recommendation of this type of behavioral intervention for HF patients.

\section{Author contributions}

Conception and design of the research: Cavalcante VN. Acquisition of data: Cavalcante VN. Analysis and interpretation of the data: Tinoco JVMP, Figueiredo LS. Writing of the manuscript: Cavalcante VN. Critical revision of the manuscript for intellectual content: Mesquita ET, Cavalcanti ACD.

\section{Potential Conflict of Interest}

No potential conflict of interest relevant to this article was reported.

\section{Sources of Funding}

There were no external funding sources for this study.

\section{Study Association}

This article is part of the thesis of master submitted by Vaisnava Cavalcante, from Universidade Federal Fluminense.

5. Falk H, Ekman I, Anderson R, Fu M, Granger B. Older patients' experiences of heart failure-an integrative literature review. J Nurs Scholarsh. 2013; 45(3): 247-55.

6. Janssen DJ, Spruit M, Uszko-Lencer NH, Schols JMGA, Schols JM, Wouters EF. Symptoms, comorbidities, and health care in advanced chronic obstructive pulmonary disease or chronic heart failure. J Palliat Med. 2011;14(6):735-43.

7. Albert N, Trochelman K, Li J, Lin S. Signs and symptoms of heart failure: are you asking the right questions? Am J Crit Care. 2010;19(5):443-52.

8. Olano-Lizarraga M, Oroviogoicoechea C, Errasti-I Saracibar-Razquin M The personal experience of living with chronic heart failure: a qualitative meta-synthesis of the literature. J Clin Nurs. 2016;25(17-18):2413-29. 
9. Eastwood J-A, Moser DK, Riegel BJ, Albert NM, Pressler S, Chung $\mathrm{ML}$, et al. Commonalities and differences in correlates of depressive symptoms in men and women with heart failure. Eur J Cardiovasc Nurs.2012;11(3):356-65.

10. Leeming A, Murray SA, Kendall M, The impact of advanced heart failure on social, psychological and existential aspects and personhood. Eur J Cardiovasc Nurs. 2014;13(2):162-7.

11. Hopp FP, Thornton N, Martin L. The lived experience of heart failure at the end of life: a systematic literature review. Health Soc Work 2010;35(2):109-17.

12. Heo S, Moser DK, Pressler SJ, Dunbar SB, Mudd-Martin G, Lennie TA Psychometric properties of the Symptom Status Questionnaire-Heart Failure. J cardiovasc Nurs.2015;30(2):136-44.

13. Blinderman CD, Homel P, Billings J, Portenoy Rk, Tennstedt SL, Symptom distress and quality of life in patients with advanced congestive heart failure. J Pain Symptom Manage. 2008;35(6):594-603.

14. Giamouzis G, Kalogeropoulos A, Georgiopoulou V, Laskar S, Smith AL, Dunbar S,et al. Hospitalization epidemic in patients with heart failure: risk factors, risk prediction, knowledge gaps, and future directions. J Card Fail. 2011;17(1):54-75.

15. Di Mauro M, Petroni R, Clemente D, Foschi M, Tancredi F, Camponetti $\mathrm{V}$, et al. Clinical profile of patients with heart failure can predict rehospitalization and quality of life. J Cardiovasc Med. 2018;19(3):98-104.

16. Kabat-Zinn J, Lipworth L, Burney R, The clinical use of mindfulness meditation for the self-regulation of chronic pain. J Behav Med 1985;8(2):163-90.

17. Gotink RA, Chu P, Busschbach JJ, Benson H, Fricchione GL, Hunink MG. Standardised mindfulness-based interventions in healthcare: an overview of systematic reviews and meta-analyses of RCTs. PLoS One 2015; 10(4): e0124344.

18. Sundquist J, Lilja A, Palmer K, Memon AA, Wang X, Johansson LM, et al. Mindfulness group therapy in primary care patients with depression, anxiety and stress and adjustment disorders: randomised controlled trial. Br J Psychiatry. 2015;206(2):128-35.

19. May RW, Bamber M, Seibert GS, Sanchez-Gonzalez MA, Leonard JT, Salsbury RA, et al. Understanding the physiology of mindfulness: aortic hemodynamics and heart rate variability. Stress. 2016;19(2):168-74.

20. Younge JO, Wery MF, Gotink RA, Utens EM, Michels M, Rizopoulos D, et al. Web-Based Mindfulness Intervention in Heart Disease: A Randomized Controlled Trial. PLoS One. 2015;10(12):e0143843

21. Fish JA, Ettridge K, Sharplin GR, Hancock B, Knott VE. Mindfulnessbased cancer stress management: impact of a mindfulness-based programme on psychological distress and quality of life. European journal of cancer care. 2014;23(3):413-21.

22. Diedrich A, Grant M, Hofmann SG, Hiller W, Berking M. Self-compassion as an emotion regulation strategy in major depressive disorder. Behav Res Ther. 2014;58:43-51.

23. Fjorback LO, Arendt M, Ornbøl E, Fink P, Walach H. Mindfulnessbased stress reduction and mindfulness-based cognitive therapy: a systematic review of randomized controlled trials. Acta Psych Scand. 2011;124(2):102-19.

24. Katterman SN, Kleinman BM, Hood MM, Nackers LM, Corsica JA. Mindfulness meditation as an intervention for binge eating, emotional eating, and weight loss: a systematic review. Eating Behaviors. 2014;15(2):197-204.

25. Huang X, Lin J, Demner-Fushman D. Evaluation of PICO as a knowledge representation for clinical questions. AMIA Annu Symp Proc. 2006; 2006:359-63.

26. Tufanaru C, Munn Z, Aromataris E, Campbell J, Hopp L. Chapter 3: Systematic reviews of effectiveness. In: Aromataris E, Munn Z (Editors). JBI Manual for Evidence Synthesis. JBI, 2020. Available from https:// synthesismanual.jbi.global

27. Moola S, Munn Z, Tufanaru C, Aromataris E, Sears K, Sfetcu R, et al. Currie M, Qureshi R, Mattis P, Lisy K, Mu P-F. Chapter 7: Systematic reviews of etiology and risk. In: Aromataris E, Munn Z (Editors). JBI Manual for Evidence Synthesis. JBI, 2020. Available from https:// synthesismanual.jbi.global

28. Curiati JA, Bocchi E, Freire JO, Arantes AC, Braga M, Guimaraes G, et al. Meditation reduces sympathetic activation and improves the quality of life in elderly patients with optimally treated heart failure: a prospective randomized study. J Altern Complement Med. 2005;11(3):465-72.

29. Sullivan MJ, Wood L, Terry J, Brantley J, Charles A, McGee V, et al. The Support, Education, and Research in Chronic Heart Failure Study (SEARCH): a mindfulness-based psychoeducational intervention improves depression and clinical symptoms in patients with chronic heart failure. Am Heart J. 2009;157(1):84-90.

30. Caldwell PH, Arthur HM, Demers C. Preferences of patients with heart failure for prognosis communication. Can J Cardiol. 2007 Aug; 23(10): 791-6.

31. Glück TM, Maercker A. A randomized controlled pilot study of a brief web-based mindfulness training. BMC Psychiatry. 2011;11:175.

32. Krusche A, Cyhlarova E, King S, Williams JMG. Mindfulness online: a preliminary evaluation of the feasibility of a web-based mindfulness course and the impact on stress. BMJ Open. 2012;2(3):e000803.

33. Morledge TJ, Allexandre D, Fox E, Fu AZ, Higashi MK, Kruzikas DT, et al. Feasibility of an online mindfulness program for stress management--a randomized, controlled trial. Ann Behav Med. 2013;46(2):137-48.

34. Rector TS, Kubo SH, Cohn JN. Validity of the Minnesota Living with Heart Failure questionnaire as a measure of therapeutic response to enalapril or placebo. Am J Cardiol. 1993;71(12):1106-7.

35. Luskin F, Reitz M, Newell K, Quinn TG, Haskell W. A controlled pilot study of stress management training of elderly patients with congestive heart failure. Neuroreport;16(17):1893-7.

36. Denollet J, Brutsaert DL. Reducing emotional distress improves prognosis in coronary heart disease: 9-year mortality in a clinical trial of rehabilitation. Circulation. 2001;104(17):2018-23.

37. Dusseldorp E, van Elderen T, Maes S, Meulman J, Kraaij V. A metaanalysis of psychoeduational programs for coronary heart disease patients. Health psychology : official journal of the Division of Health Psychology, Am Psychol Assoc.1999;18(5):506-19.

38. Rechenberg K, Cousin L, Redwine L. Mindfulness, Anxiety Symptoms, and Quality of Life in Heart Failure. J Cardiovasc Nurs. 2020;35(4):358-63.

39. Coats AJS. Advances in the non-drug, non-surgical, non-device management of chronic heart failure. Int J Cardiol. 2005;100(1):1-4 